\title{
Review Paper: Assessing Thoracic and Lumbar Spinal Curvature Norm: A Systematic Review
}

\author{
Aliasghar Norasteh $^{1}$ (D), Elham Hajihosseini ${ }^{1^{*}}$ (D), Sara Emami ${ }^{1}$ (D), Hamed Mahmoudi ${ }^{1}$ (D)
}

1. Department of Corrective Exercises and Sports Injuries, School of Physical Education and Sports Sciences, University of Guilan, Rasht, Iran

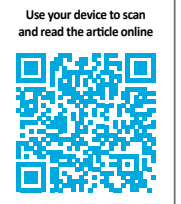

Crtation Norasteh A, Hajihosseini E, Emami S, Mahmoudi H. Assessing Thoracic and Lumbar Spinal Curvature Norm: A Systematic Review. Physical Treatments. 2019; 9(4):183-192. http://dx.doi.org/10.32598/ptj.9.4.183

dol' http://dx.doi.org/10.32598/ptj.9.4.183

\section{(1) (8)}

Article info:

Received: 13 Feb 2019

Accepted: 10 Aug 2019

Available Online: 01 Oct 2019

Keywords:

Norm, Kyphosis, Thoracic spine, Lordosis, Lumbar spine

\begin{abstract}
A B S T RA C T
Purpose: The quality and condition of the human body are of particular importance. This is because the positive and negative changes resulting from this matter could affect other conditions. The skeletal condition of the spine is an essential part of a person's physical condition. Recognizing correct positions has always attracted the attention of sports scientists. The present study reviewed the normative data of the thoracic and lumbar curvature.

Methods: We investigated the studies conducted from 1980-2016. We studied and used related articles that measured spinal curvatures and investigated invasive and non-invasive methods. The authors reported previous studies without any bias.

Results: The obtained results indicated that spine norms are different in research reports. Thus, further investigating this subject is required for recognizing, categorizing, screening, and decreasing the prevalence of spinal deformities.

Conclusion: We reviewed the studies on the prevalence of spinal abnormalities and the provision of natural alignment and the extent of injury to the area in athletes. The relevant data suggested a great variation in applying measurement methods, as well as the homogeneity between the studied communities. Therefore, comparing the present results and categorizing studies should be performed with great caution.
\end{abstract}

\section{Highlights}

- The prevalence of spinal biomechanical changes in different research reports.

\section{Plain Language Summary}

To identify, classify, screen, and ultimately reduce the prevalence of spinal biomechanical changes, it is necessary to conduct and expand such studies.

\section{* Corresponding Author:}

Address: Department of Corrective Exercises and Sports Injuries, School of Physical Education and Sports Sciences, University of Guilan, Rasht, Iran. Phone: +98 (936) 0441429

E-mail: hosseinielham1988@gmail.com 


\section{Introduction}

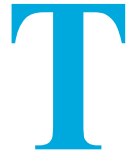

he quality and status of the human body are of particular importance. This is because the positive and negative changes resulting from it affect other conditions [1]. The spine skeletal status is an essential part of one's physical condition. The spine is among the most significant components of the upper body. In addition to protecting the spinal cord, it is one of the most sensitive body parts; it highly impacts movement and maintaining the rigidity or stiffness of the human body framework [2]. This moving part can provide different forms to the human body and design various situations.

Moreover, it could develop an appropriate appearance and stature for the human body [1-3]. Spine, as a body axis, has specific structural features to meet mechanical needs, such as stability and mobility [4]. One of such features is arches that majorly affects strengthening the spine. These arches not only increase the absorption of pressure by the spine but also contribute to the muscles' efficiency, associated with the spine [4]. The arches of spine influence and compensate each other; therefore, increased kyphosis can affect spinal biomechanical changes affecting other arches, like lumbar lordosis. Accordingly, by decreasing or increasing the arches, the spine will biomechanically move towards instability [5]. The proper and normal organizing of the skeletal structure in terms of biomotor and biomechanical matters facilitates the performance of basic activities and the daily living activities of individuals. Any abnormal status of upper body skeletal structure, especially the spine, damages the person's overall stature and appearance and affects the natural action of other vital organs in the chest and abdomen [1]. Recognizing spine abnormalities has always drawn the attention of sports science experts. Most of them believe that middle school students are at a critical period due to changes resulting from physical growth. Physical-motor weaknesses at these ages sometimes remain constant after puberty. Accordingly, individuals might be affected by lifetime adverse physical conditions [5]. Some studies conducted in Iran have reported a high prevalence of these abnormalities. Sazvar studied male guidance school students in Zanjan; it was concluded that $93.8 \%$ of the studied students had at least one spinal abnormality. In this study, $14.6 \%$ and $24.4 \%$ of the samples had kyphosis and lordosis, respectively [2].

Assessing abnormality and determining the degree of spinal curvature and assessing the norm is some form of judgment. Thus, a wider range of accurate information about them could help to reduce the odds of judg- mental errors $[6,7]$. Transforming numerical values resulting from the instrument to scores, according to the given individual characteristics, will only be valid when the individual tests' numerical value is compared with the homogeneous groups at equal conditions $[8,9]$. The exact range of thoracic kyphosis and lordosis is mainly assessed by X-rays; however, limited studies have evaluated spinal curvature in the sagittal plane. Furthermore, most studies have investigated the lateral inclinations of the spine (e.g., scoliosis) [10]. Besides, most of these studies disregarded reporting details on kyphosis and lordosis. For example, they overlooked details on the mean range of kyphosis and lordosis in growing children. They have also failed to report whether angles or the process of changes are important or not; the possibility of the natural curvatures of these arches to be plotted during growth, and the importance of the ratio of arches, in comparison with the individual ones. A reason for an inadequate date on the sagittal spinal plane in upright position posture is the lack of a simple, inexpensive, and non-invasive technique to describe and determine the normal mean range of these spinal curvatures. These curvatures on the sagittal plane cannot be measured using an X-ray of the spine. Moreover, this method cannot be used to screen large populations due to being harmful to children and costly [11].

The thoracic kyphosis angle is the initial inclination of the spine, i.e., composed of 12 vertebrae. The thoracic kyphosis angle increases with aging; such an increase is more frequent in females $[12,13]$. Hyper-kyphosis, or an increase in the chest curvature more than the normal range, is among the prevalent spinal disorders. Biomechanical data suggested that increased thoracic kyphosis may be associated with a higher load on the spine and trunk force in an upright position; this may speed up the degradation process of muscles and increase the pain and spinal dysfunction $[14,15]$.

Increased thoracic kyphosis is also associated with reduced physical function, respiratory function impairment, increased neck pain, headache, and discomforts, like subacromial pain syndrome $[16,17]$. Despite several studies on the normal range of thoracic angle, there is a controversy on its value. For example, in a study conducted by Willner and Johnson, the lowest value of kyphosis was observed between the ages of 10 and 12 years. Besides, the mean kyphosis angle in 8- and 16-year-olds was 35 and 44 degrees, respectively [18]. The study investigated 2-20-year-old boys. Accordingly, Proctor and Bleck reported a 27-degree angle as a normal one [19]. The mean size of thoracic kyphosis in the study conducted by Voutsinas and MacEwen was 38.1 degrees 
in white boys, 34.3 degrees in black boys, 38.5 degrees in white girls, and 36.9 degrees in black girls [20]. Based on various research studies, the kyphosis value in adults varies from 35 to 37 degrees; however, such studies have been conducted on heterogeneous populations [21, 22]. Boseker et al. reported the normal range of kyphosis to be 20-50 degrees [23]. Such great differences may be due to differences in the study tools, sample characteristics (age, gender, etc.), and research limitations that certainly affect spine curvature. They may also be related to factors, such as age, gender, geographic area, and race, i.e., claimed to affect this curvature [22-24]. Despite various studies conducted around the world on the normal range of thoracic kyphosis, each region seems to need its value. Additionally, with increasing lordosis, spine biomechanics changes led to its non-alignment due to increased loading on the facet joints and increased shear force at the lumbosacral junction [25-28].

Studies suggested an increase in clinical and functional importance of diagnosing lumbar lordosis, i.e., a key feature in maintaining balance in the sagittal plane [29-31]. Balance at the sagittal plane or natural vertebral-sagittal alignment in standing position is the postural goal of ergonomics, physiotherapy, and surgical interventions. Although various lumbar lordosis and kyphosis may match the standard criteria, it is difficult to certainly state whether the researcher, surgeon, therapist, or patient has achieved the postural goal. In this study, the keywords of "spine," "vertebra," "lordosis," "waist," "posture," "pathology," "size" and a combination of them were searched in the databases of Google Scholar, Magiran, ScienceDirect, PubMed, and SID.

The obtained results reported the angles of lumbar lordosis among children, as follows: between upper surface of L1 and lower surface of S1: 51.3 degrees; from the bottom of L1 to upper surface of S1: 54.8 degrees, above L2 to high surface of S1: 49 degrees; above L1 to upper surface of L5: 31.5 degrees, and between upper surface L1 and lower surface L5: 39.6 degrees [31]. Another study investigated the lumbar lordosis of 149 healthy adults. They included 76 males and 73 females with a mean age of 50 years. The Mean \pm SD Lumbar Lordosis Angle (LLA), Lumbosacral Angle (LSA), and Sacral Inclination Angle (SIA) were 33.2 $\pm 12.1,11.4 \pm 4.7$, and $26.4 \pm 10$ degrees, respectively. This study revealed a high correlation between LLA and SIA $(r=0.883$, $\mathrm{P}=0.0001$ ); LLA was an ideal parameter for evaluating the LLA [32]. Several studies have investigated spinal curvature in the sagittal plane; however, no study was found on determining the norm of kyphosis and lumbar lordosis. Therefore, this study aimed to reach a more ac- curate conclusion by reviewing the conducted studies. We determined the specific size and norm range for the level of increase or decrease in spinal curvatures.

\section{Materials and Methods}

The studies conducted from 1980-2016 were reviewed in this article. For this purpose, the keywords of "lordosis, spinal angle, normal range, thoracic kyphosis, spinal curvature, assessment, norm, and non-invasive methods" were searched in Pub Med, ScienceDirect, Google Scholar, Magiran, and SID databases. A manual searching was also performed for finding the articles that were not possible to obtain through a database search. Then, after excluding duplicate articles based on the inclusion criteria, the articles containing information on the thoracic and lumbar spine were selected. Inclusion criteria included all articles related to spinal arches and the assessment of invasive and non-invasive methods of measuring arches. The researcher had no bias in collecting and submitting papers and did not apply his experiences or theories and merely reported the available evidence. In the first stage, 35 articles related to the research subject were selected. Among these articles, the articles that $>70 \%$ of their content was related to the subject of spinal norms were selected based on a purposive sampling method. Thus, the selected articles and three books were considered as the sources of this research.

\section{Results}

The selected studies were divided into three groups based on different spine regions. The first, second, and third groups included the articles that have investigated the thoracic kyphosis, the lumbar lordosis, and both of these arches, respectively.

\section{Thoracic arches of the spine}

In 2000, Busker et al. investigated the radiographic results of 121 healthy adolescents and determined the healthy angle of kyphosis for these subjects. They reported this angle at the normal ranged 20-50 degrees [23]. Ball et al. explored 250 healthy 30-79-year-old women and argued that the lumbar lordosis degree increased with aging. They also documented that the highest increase in lumbar lordosis occurred between 50 and 59 years of age [33]. Shamsi et al. measured 582 male students in terms of the normal kyphosis range and reported a mean kyphosis value in these 13-18-year-olds. The researchers also stated that this curvature increased from the age of 13-16 years and slightly decreased from the age of $16-18$ years [15]. 


\section{Lumbar arches of the spine}

Yodas et al. indicated that stopping an increase in the lumbar arch angle and a flexible ruler supported its reduction at higher ages. They stated that, after the age of 60 years, the lumbar arch angle decreased without any increase (mean arch: 49.5 degrees in females and 43 degrees in males) [24]. Hegazy examined the anatomy of the lumbar lordosis on a sagittal plate in Egyptian adults [34]. Normal Magnetic resonance imaging (MRI) of the lumbar spine obtained from 93 patients (46 males and 47 females, aged 25-57 years) were retrospectively reviewed. Taweetanalarp and Purepong measured lumbar curvature in two regions of the lumbar spine in healthy and overweight adults. They also compared the upper and lower lordosis and reported the Mean $\pm \mathrm{SD}$ value of upper lordosis (distance between T12 and L4) 14.5 \pm 5.9 for the healthy-weight subjects and Mean \pm SD scores of lower lordosis (from L4 to S2) for this group was $16.1 \pm 6.4$. In overweight patients, the Mean \pm SD lordosis value was $7.8 \pm 7.4$ for upper lordosis and 22.9 \pm 7.9 for lower lordosis [35]. The values obtained for the LLA ranged from 30 to 67 degrees and were higher in females (52.20 degrees) compared to males (41.98 degrees). Hay et al. investigated the lumbar lordosis curvature in males and females using a computed tomography (CT) scan. After examining the hospital data of 158 patients ( 81 males and 77 females), they reported that the lordosis curvature was significantly larger in females than that of males (Mean \pm SD length of lordosis curvature was $182 \pm 13 \mathrm{~cm}$ in females and $19.4 \pm 1.5 \mathrm{~cm}$ in males) [36]

\section{Kyphosis and lordosis of the spine}

Sidhou and Singhal conducted a comprehensive study on $>1000$ females aged 20-80 years in India using a flexible ruler. The achieved results suggested a significant increase in the lumbar lordosis degree from the age of $45-70$ years (between 0.5 and $0.75 \mathrm{~cm}$ ); however, the LLA decreased from the age of 70 years onwards $(0.25$ 0.3 ) [38]. Furthermore, Geliv and Walpone investigated the changes in kyphosis and lumbar lordosis during the growth period. They compared 350 males with 368 females aged between 5 and 20 years. They reported that the kyphosis increased linearly from 25 degrees at the age of 7 to 38 degrees at the age of 19 years; similarly, lordosis increased linearly from 22 at the age of 5-32 years degrees at the age of 20 years [37]. Kamali investigated and formulated a norm for kyphosis and lordosis in high school students in Gilan Province, Iran. After measuring the arches in 402 high school girls, it was reported that 15 -year-old girls had a Mean \pm SD lordosis angle of 45.27 \pm 15.22 degrees and a Mean \pm SD kyphosis angle of $93.73 \pm 8.02$ degrees. Besides, Mean \pm SD lordosis angle in 16- and 17-year-old girls were $46.67 \pm 17.87$ and $46.53 \pm 12.57$, respectively, and Mean \pm SD kyphosis angle in these two age groups was reported at $41.91 \pm 7.89$ and 41.18 \pm 8.38 degrees, respectively [39]. Rajabi and Latifi formulated the healthy range for kyphosis and lordosis in Iranian males and females. The lordosis and kyphosis of the samples were measured using a flexible ruler. Investigating 2400 people, including 1200 males and 1200 females in 5 age groups selected from different segments of society and 5 geographic regions of Iran, these researchers reported the mean and healthy range of kyphosis and lordosis [40]. In a study on 636 healthy 12-17-year-old boys, the mean kyphosis and lordosis values for 6 age groups was reported, using a flexible ruler. The value of lordosis and kyphosis varied in different age groups and the minimum and maximum values of kyphosis were reported at the age groups of 12 and 17 years, respectively. The minimum lordosis was observed in the age group of 14 years. In this study, the mean kyphosis increased with aging [11].

\section{Discussion}

Abnormal physical posture and the body's inability to maintain the body stature in addition to physical complications can have adverse psychological consequences, such as depression, isolation, defects in responsibility, the lack of confidence, and early fatigue. The results of the studies mentioned above indicated that the prevalence of spinal postural abnormalities is high and varies in different research reports. Thus, to identify, classify, screen, and ultimately reduce the prevalence of these abnormalities, it is necessary to conduct and expand such studies. A review of studies on the prevalence of spinal abnormalities revealed a high variation in the use of measurement methods, and lower homogeneity was observed among the studied populations in different studies. Thus, the collected results should be compared and categorized with caution. For example, early studies conducted in Iran have used a chessboard to measure the kyphosis and lordosis angles, i.e., a qualitative method without sufficient validation.

The use of digital cameras, 3D analysis method [12,35, 45], spinal pantograph [37], and radiography [23] were other methods used in the studies. Numerous studies have applied flexible rulers for this measurement. With a closer look at the measurement method through a flexible ruler, we realized differences in the measurement details among these studies that might affect the obtained results. For example, T1 and T12 [11-42], T2, and T12 [15-40] landmarks have been used in the measurement 
Table 1. Thoracic arches and Kyphosis and lordosis of the spine

\begin{tabular}{|c|c|c|c|c|c|c|c|c|c|}
\hline \& & 高 & Year & Objective & Sample Size & $\underset{\&}{8}$ & $\begin{array}{c}\text { Assessment } \\
\text { Tool }\end{array}$ & Arch Site & Mean Arch & Descriptions \\
\hline$\rightarrow$ & 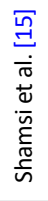 & 空 & $\begin{array}{l}\text { The determination } \\
\text { of healthy range of } \\
\text { kyphosis in male } \\
\text { students }\end{array}$ & $\begin{array}{l}582 \text { individu- } \\
\text { als }\end{array}$ & 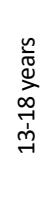 & $\begin{array}{l}\text { Flexible } \\
\text { ruler }\end{array}$ & 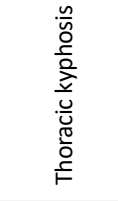 & 35.49 degrees & $\begin{array}{l}\text { The kyphosis increased from 13- } \\
16 \text { years and slightly decreased } \\
\text { from } 16-18 \text { years old. }\end{array}$ \\
\hline N & 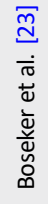 & ષ્సి & $\begin{array}{l}\text { Determining the } \\
\text { healthy angle of } \\
\text { kyphosis }\end{array}$ & $\begin{array}{l}121 \text { individu- } \\
\text { als }\end{array}$ & 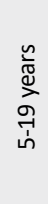 & Radiography & 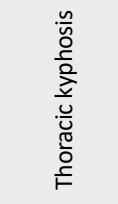 & 20-50 degrees & $\begin{array}{c}\text { There was no difference among } \\
\text { various age groups and between } \\
\text { the two genders. }\end{array}$ \\
\hline$m$ & 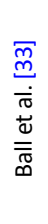 & ठ্ণ & $\begin{array}{l}\text { The effect of spinal } \\
\text { extension exercises } \\
\text { on the prevention } \\
\text { of kyphosis }\end{array}$ & $\begin{array}{l}250 \text { individu- } \\
\text { als }\end{array}$ & 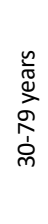 & $\begin{array}{l}\text { Radiography } \\
\text { and spine } \\
\text { board }\end{array}$ & 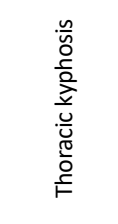 & $1.7-12 \mathrm{~cm}^{2}$ & $\begin{array}{c}\text { The lumbar lordosis degree } \\
\text { increased with aging and the } \\
\text { largest lumbar lordosis increase } \\
\text { occurred between } 50 \text { and } 59 \\
\text { years of age. } \\
\text { A 2.8-degree reduction in angle of } \\
\text { kyphosis was also observed. }\end{array}$ \\
\hline+ & 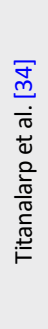 & 岂 & $\begin{array}{l}\text { Measuring upper } \\
\text { and lower lordosis } \\
\text { in adults with } \\
\text { normal BMI and } \\
\text { overweight }\end{array}$ & 60 individuals & 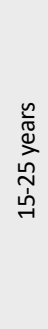 & $\begin{array}{l}\text { Flexible } \\
\text { ruler }\end{array}$ & 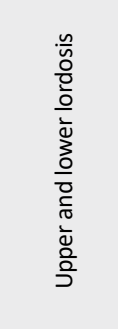 & $\begin{array}{l}\text { In subjects with } \\
\text { normal BMI, } \\
\text { Mean } \pm \text { SD upper } \\
\text { lordosis: } 14.5 \pm 5.9 ; \\
\text { lower lordosis: } \\
16.1 \pm 6.4 ; \\
\text { in overweight } \\
\text { subjects, lordosis: } \\
\text { 18.8 } 7.4 \text { and lower } \\
\text { lordosis: } 22.9 \pm 7.9\end{array}$ & $\begin{array}{l}\text { The mean lumbar angle was } \\
\text { significantly higher in the over- } \\
\text { weight group than that of the } \\
\text { normal weight group. }\end{array}$ \\
\hline in & 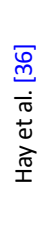 & 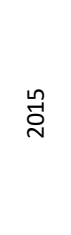 & $\begin{array}{l}\text { Investigating lumbar } \\
\text { lordosis in men and } \\
\text { women }\end{array}$ & $\begin{array}{l}158 \text { individu- } \\
\text { als }\end{array}$ & 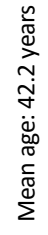 & CT scan & $\begin{array}{l}\frac{n}{n} \\
\frac{0}{0} \\
\frac{0}{0}\end{array}$ & $\begin{array}{c}\text { Mean } \pm S D \text { lordosis } \\
\text { length: was } 182 \pm 13 \\
\mathrm{~cm} \text { in females and } \\
19.4 \pm 1.5 \mathrm{~cm} \text { in } \\
\text { males }\end{array}$ & $\begin{array}{l}\text { The lordosis was significantly } \\
\text { larger in females than males. }\end{array}$ \\
\hline 6 & 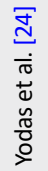 & ષ્ণ & $\begin{array}{l}\text { The effect of age } \\
\text { and gender on } \\
\text { lordosis }\end{array}$ & $\begin{array}{l}119 \text { males } \\
\text { and } 116 \\
\text { females }\end{array}$ & 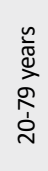 & $\begin{array}{l}\text { Flexible } \\
\text { ruler }\end{array}$ & $\begin{array}{l}\frac{0}{10} \\
\frac{0}{0} \\
\frac{0}{0}\end{array}$ & $\begin{array}{l}\text { The mean arch: } \\
49.5 \text { degrees in } \\
\text { females and } 43 \\
\text { degrees in males }\end{array}$ & $\begin{array}{l}\text { After the age of } 60 \text { years, the } \\
\text { lumbar angle decreased and no } \\
\text { increase was observed. }\end{array}$ \\
\hline r & 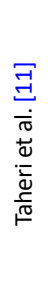 & సี & $\begin{array}{l}\text { The determination } \\
\text { of the norm range } \\
\text { of kyphosis and } \\
\text { lordosis }\end{array}$ & 636 boys & 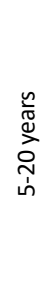 & $\begin{array}{l}\text { Flexible } \\
\text { ruler }\end{array}$ & 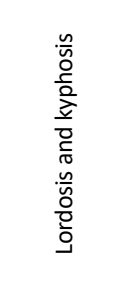 & $\begin{array}{l}\text { The Mean } \pm S D \\
\text { value of kyphosis } \\
\text { ranged from } \\
39.64 \pm 8.70 \text { to } \\
46.02 \pm 8.67 \text {. The } \\
\text { value of lordosis } \\
\text { ranged from } \\
44.96 \pm 10.27 \text { to } \\
44.45 \pm 10.42\end{array}$ & $\begin{array}{l}\text { The minimum kyphosis was } \\
\text { reported in the age group of } 12 \\
\text { years, and the maximum was } \\
\text { reported in the age group of } 17 \\
\text { years. } \\
\text { Minimum lordosis was observed } \\
\text { in } 14 \text { years of the old group. The } \\
\text { mean kyphosis increases with } \\
\text { increasing age. }\end{array}$ \\
\hline$\infty$ & 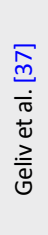 & ठิે & $\begin{array}{l}\text { The investigation of } \\
\text { the changes of the } \\
\text { kyphosis and lordo- } \\
\text { sis during growth }\end{array}$ & $\begin{array}{l}350 \text { males } \\
\text { and } 368 \\
\text { females }\end{array}$ & 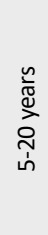 & $\begin{array}{l}\text { Spinal Pan- } \\
\text { tograph }\end{array}$ & $\begin{array}{l}\frac{n}{0} \\
\frac{0}{0} \\
\frac{2}{2} \\
\frac{1}{0} \\
\frac{0}{0} \\
\frac{n}{0} \\
\frac{0}{0} \\
0\end{array}$ & $\begin{array}{l}\text { Kyphosis was } 25 \\
\text { to } 37 \text { degrees, and } \\
\text { lumbar lordosis } \\
\text { was } 22 \text { to } 32 \\
\text { degrees }\end{array}$ & $\begin{array}{l}\text { The kyphosis arch increases } \\
\text { linearly from } 25 \text { degrees at the } \\
\text { age of } 7-38 \text { years degrees at the } \\
\text { age of } 19 \text { years, and the lordosis } \\
\text { arch increases linearly from } 22 \\
\text { degrees at the age of 5-32 years } \\
\text { degrees at the age of } 20 \text { years }\end{array}$ \\
\hline
\end{tabular}




\begin{tabular}{|c|c|c|c|c|c|c|c|c|c|}
\hline ¿̇̉ & 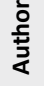 & Year & Objective & Sample Size & $\underset{\leftarrow}{\stackrel{g}{\circ}}$ & $\begin{array}{c}\text { Assessment } \\
\text { Tool }\end{array}$ & Arch Site & Mean Arch & Descriptions \\
\hline$\sigma$ & 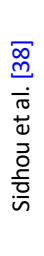 & $\underset{\infty}{\infty}$ & $\begin{array}{l}\text { Investigating age- } \\
\text { related changes } \\
\text { in lordosis and } \\
\text { kyphosis }\end{array}$ & 1000 females & 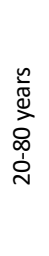 & $\begin{array}{c}\text { Flexible } \\
\text { ruler }\end{array}$ & $\begin{array}{l}\frac{n}{5} \\
0 \\
\frac{1}{0} \\
\frac{2}{2} \\
\frac{0}{0} \\
\frac{0}{0} \\
\frac{n}{n} \\
\frac{0}{0} \\
0 \\
0\end{array}$ & $\begin{array}{c}\text { An increase in } \\
\text { kyphosis was } \\
\text { observed between } \\
0.5 \text { and } 0.75 \mathrm{~cm} \text {, } \\
\text { and a reduction in } \\
\text { the lordosis angle } \\
\text { was equal to } 0.25 \\
\text { to } 0.3 \mathrm{~cm}\end{array}$ & $\begin{array}{l}\text { The lordosis angle significantly } \\
\text { increased from the age of } 45-70 \\
\text { years, but the lumbar angle de- } \\
\text { creased from the age of } 70 \text { years } \\
\text { onwards. }\end{array}$ \\
\hline 억 & 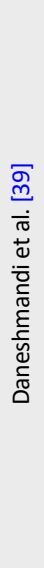 & ㅇํํ & $\begin{array}{l}\text { Investigating and } \\
\text { formulating spinal } \\
\text { arches in students }\end{array}$ & 402 girls & 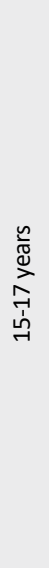 & $\begin{array}{l}\text { Flexible } \\
\text { ruler }\end{array}$ & 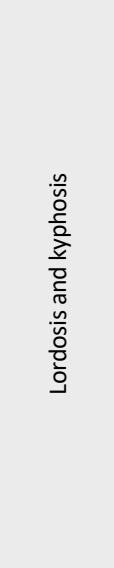 & $\begin{array}{c}\text { 15-year-old girls } \\
\text { had Mean } \pm S D \\
\text { lordosis angle of } \\
45.27 \pm 15.22 \text { and } \\
\text { kyphosis angle of } \\
93.73 \pm 8.02 ; \\
16 \text {-year-old girls } \\
\text { had Mean } \pm S D \text { an- } \\
\text { gular lordosis of } \\
46.67 \pm 14.76 \text { and } \\
\text { kyphosis angle of } \\
41.91 \pm 7.89 ; \\
17-y e a r-o l d \text { girls } \\
\text { had Mean } \pm S D \\
\text { lordosis angle of } \\
46.53 \pm 12.57 \text { and } \\
\text { kyphosis angle of } \\
41.18 \pm 8.38\end{array}$ & $\begin{array}{l}\text { The degree of lordosis angle in- } \\
\text { creased significantly from the age } \\
\text { of } 45-70 \text { years, but the lumbar } \\
\text { angle decreased from the age of } \\
70 \text { years onwards. }\end{array}$ \\
\hline$\exists$ & 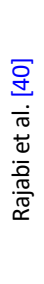 & 옹 & $\begin{array}{l}\text { Formulating the } \\
\text { healthy ranges of } \\
\text { the curvatures of } \\
\text { the lumbar spine } \\
\text { of Iranian men and } \\
\text { women }\end{array}$ & 2400 girls & 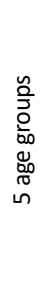 & $\begin{array}{l}\text { Flexible } \\
\text { ruler }\end{array}$ & $\begin{array}{l}\frac{n}{0} \\
\frac{0}{0} \\
\frac{2}{2} \\
\frac{2}{0} \\
\frac{0}{0} \\
\frac{0}{n} \\
\frac{n}{1} \\
\frac{0}{0} \\
\frac{0}{9}\end{array}$ & $\begin{array}{l}\text { Mean } \pm \text { SD lumbar } \\
\text { lordosis was } \\
46.99 \pm 14 \text { in } \\
\text { females and } 38.60 \\
\pm 11 \text { in males }\end{array}$ & $\begin{array}{l}\text { A comparison of lumbar lordosis } \\
\text { between males and females } \\
\text { suggested that the mean lumbar } \\
\text { lordosis was higher among } \\
\text { females compared to males. Also, } \\
\text { the degree of lumbar lordosis } \\
\text { increased with aging, i.e., uniform } \\
\text { in both genders and follows a } \\
\text { similar trend. }\end{array}$ \\
\hline
\end{tabular}

of kyphosis. These differences are also true for the measurement of the lordosis angle. Rajabi et al. conducted a comprehensive study on 2400 Iranians. This sample included 1200 males and 1200 females in 5 age groups of $\leq 14$ years, 15-24 years, 25-44 years, 45-64 years, and $\geq 65$ years. Based on the results, the Mean \pm SD norm of kyphosis were $40.82 \pm 8.4$ in boys $\leq 14$ years; $41.77 \pm 10$ at the age group of $15-24$ years; $42.80 \pm 10$ at the age group of 25-44 years; $43.19 \pm 8.48$ at the age group of 45-64 years, and $43.37 \pm 9.98$ at the age group of 65 years.

A study by Rajabi and Latifi on lordosis suggested that this value increases in both genders with aging. They argued than an increase in lordosis continues in women up to 45-64 years of age; however, after this period, it gradually decreases in women [40]. The pattern of changes in lordosis among men is similar to that of women; however, its reduction begins at the age of 44 years in men and increases rapidly after the age of 60 years. Given increasing lordosis with aging, various researchers have also reported that age is an important factor in increasing lordosis [12, 43]. Rajabi and Latifi also reported an increase in lordosis and kyphosis at the growth ages is higher in girls than that of boys and other age groups. This difference is justified by the fact that developmental mutation in girls occurs two years earlier than that of the boys [44].

Rajabi and Latifi stated that the value of kyphosis increases with aging, and it follows a similar trend in both genders. The present results indicated that the total mean of lordosis (regardless of age) was 42.39 in males and 42.27 in females, i.e., approximately equal in both genders or slightly higher in males. Millen and Williamson found that although the lordosis increases in both genders with aging, this increase is greater among females. In general, increased lordosis with aging has been supported in most studies [12, 46-49]. In this regard, longitudinal and cross-sectional studies have reported an increase in lordosis with aging [45]. This trend has been supported by invasive measurement methods, like Xrays $[12,45]$ and by non-invasive measurement devices [38]; however, some researchers $[45,50]$ have reported that this increase is more apparent after the age of 40 
years in females [12]. Reduced muscle strength and endurance resulted from aging decrease the spine-holding muscles; this may be a major cause of lordosis in both genders. In aging, spine changes tend to increase cervical curvature and kyphosis and decrease lordosis. The need to sit and bend the thighs and knees, especially in the elderly, results in reduced lordosis and increased kyphosis. During aging, the spine is inclined towards hyper-kyphosis, part of which depends on factors, such as reduced muscle strength, centrum deformity, reduced mobility, osteoporosis, the shortening of the abdominal muscles, the stiffness of the ligaments and discs, and one's lifestyle [40].

Mika et al. (2005) highlighted that in the spine with osteoporosis, back muscle weakness is more associated with reduced bone mass in the occurrence of spinal deformities [51]. These results reflect that the differences in Back Extensor Strength (BES) of the healthy group and osteoporotic group can be due to pain, discomfort, and of the improper stimulation of these muscles [5052]. Sianaki et al. (1996) reported that BES decreased, and the kyphosis angle increased with aging. Therefore, age is a crucial factor in the relationship between BES and kyphosis angle [52]. Thus, back extensor muscles play a key role in maintaining the thoracolumbar spine alignment. Accordingly, increased kyphosis angle may not occur merely due to reduced bone mass; postural deformities in patients with osteoporosis are strongly associated with soft tissue changes in the spine, especially the back muscles.

\section{Conclusion}

This study was descriptive in terms of nature and its objective was to prepare an index for lordosis and kyphosis variables. Thus, its results can be used as a basis for further comparisons and judgments on the degree of lordosis and kyphosis in the men and women of different ages across the country, considering the research conditions.

\section{Ethical Considerations}

\section{Compliance with ethical guidelines}

All ethical principles were considered in this article.

\section{Funding}

This research did not receive any specific grant from funding agencies in the public, commercial, or not-forprofit sectors.

\section{Authors' contributions}

All authors contributed in designing, running, and writing all parts of the research.

\section{Conflict of interest}

The authors declared no conflict of interest.

\section{References}

[1] Mousavi Gilani R, Sokhangouyi R. [Comparative study of prevalence of spine abnormalities in male and female students of Zahedan University of Medical Sciences (Persian)]. Olympic Quarterly. 2001; 9(3,4):73-81.

[2] Norasteh AA, Hosseini R, Daneshmandi H, Shah Heidari S, [Balance assessment in students with Hyperkyphosis and Hyperlordosis (Persian)]. Journal of Sport Medicine. 2014; 6(1):57-71. [DOI:10.22059/jsmed.2014.50131]

[3] Ryan JL, Starkey C. Evaluation of orthopedic and athletic injures. Philadelphia: FA Davis Company; 2002.

[4] Gelb DE, Lenke LG, Bridwell KH, Blanke K, McEnery KW. An analysis of sagital spinal alignment in 100 asymptomatic middle and older aged volunteers. Spine. 1995; 20(12):13518. [DOI:10.1097/00007632-199520120-00005] [PMID]

[5] Sinaki M, Mikkelsen BA. Postmenopausal spinal osteoprosis: Flexion versus extension exercises. Archives of Physical Medicine and Rehabilitation. 1984; 65(10):593-6.

[6] Post RB, Leferink VJ. Spinal mobility: Sagital range of motion measured with the spinalmous, a new noninvasive device. Archives of Orthopaedic and Trauma Surgery. 2005, 124(3):187-92. [DOI:10.1007/s00402-004-0641-1] [PMID]

[7] Loebl WY. Measurement of spinal posture and range of spinal movement. Rheumatology. 1967; 9(2):103-10. [DOI:10.1093/rheumatology/9.3.103] [PMID]

[8] Guermazi M, Ghroubi S, Kassism L. Validity and reliability of spinal mouse to assess lumbar flexion. Annals of Physical Rehabilitation and Medicine. 2006; 49(4):172-9. [DOI:10.1016/j.annrmp.2006.03.001] [PMID]

[9] Amonoo-Kuofi HS. Changes in the lumbosacral angle, sacral inclination and the curvature of the lumbar spine during ageing. Acta Anatomica. 1992; 145(4):373-7. [DOI:10.1159/000147392] [PMID]

[10] Harvey Z, Chamis M, Lin R. The Impact of Lateral Pads versus Posterolateral Pads in the Management of Idiopathic Scoliosis. Journal of Prosthetics and Orthotics. 2002; 14(4):165-9. [DOI:10.1097/00008526-200212000-00007

[11] Taheri Tizabi AA, Mahdavinejad R, Azizi A, Jafarnejadgero $\mathrm{T}$, Sanjari M. Investigation of sagittal curves of spinal column and establishing the norm of thoracic kyphosis and lumbar lordosis. World Journal of Sport Sciences. 2012; 6(1):80-3. 
[12] Fon GJ, Pitt MJ, ThiesJr AC. Thoracic kyphosis: Range in normal subjects. The American Journal of Roentgenology. 1980; 134(5):979-83. [DOI:10.2214/ajr.134.5.979] [PMID]

[13] Nishiwaki Y, Kikuchi Y, Araya K. Association of thoracic kyphosis with subjective poor health, functional activity and blood pressure in the community-dwelling elderly. Environmental Health and Preventive Medicine. 2007; 12(6):246-50. [DOI:10.1007/BF02898031] [PMID] [PMCID]

[14] Briggs AM, Wrigley TV, Tully EA, Adams PE, Greig AM, Bennell KL. Radiographic measures of thoracic kyphosis in osteoporosis: Cobb and vertebral centroid angles. Skeletal Radiology. 2007; 36(8):761-7. [DOI:10.1007/s00256-007-02848] [PMID]

[15] Shamsi MB, Veisi K, Karimi L, Sarrafzadeh J, Najafi F. Normal range of thoracic kyphosis in male school children. Hindawi Publishing Corporation. 2014; 159465:1-5. [DOI:10.1155/2014/159465] [PMID] [PMCID]

[16] Grimsby O, Gray J. Interrelation of the spine to the shoulder girdle. Physical Therapy of the Shoulder. New York: Churchill Livingstone; 1997.

[17] Gray JC, Grimsby O. Interrelationship of the spine, rib cage, and shoulder. In: Donatelli R, editor. Physical Therapy of the Shoulder. London: Churchill Livingstone; 2004. [DOI:10.1016/B978-044306614-6.50007-7] [PMID]

[18] WillnerS, Johnson B. Thoracic kyphosis and lumbar lordosis during the growth period in children. Acta Paediatrica Scandinavica. 1983; 72(6):873-8. [DOI:10.1111/j.1651-2227.1983. tb09833.x] [PMID]

[19] Propst Proctor SL, Bleck EE. Radiographic determination of lordosis and kyphosis in normal and scoliotic children. Journal of Pediatric Orthopaedics. 1983; 3(3):344-6. [DOI:10.1097/01241398-198307000-00013] [PMID]

[20] Voutsinas SA, MacEwen GD. Sagittal profiles of the spine. Clinical Orthopaedics and Related Research. 1986; 210:23542. [DOI:10.1097/00003086-198609000-00034]

[21] Bernhardt B, Bridwell KH. Segmental analysis of the sagittal plane alignment of the normal thoracic and lumbar spines and thoracolumbar junction. Spine. 1989; 14(7):71721. [DOI:10.1097/00007632-198907000-00012] [PMID]

[22] Stagnara P, Mauroy JC, Dran G. Reciprocal angulation of vertebral bodies in a sagittal plane: Approach to references for the evaluation of kyphosis and lordosis. Spine. 1982; 7(4):335-42. [DOI:10.1097/00007632-198207000-00003] [PMID]

[23] Boseker EH, Moe JH, Winter RB, Koop SE. Determination of "normal" thoracic kyphosis: A roentgenographic study of 121 "normal" children. Journal of Pediatric Orthopaedics. 2000; 20(6):796-8. [DOI:10.1097/01241398-200011000-00019] [PMID]

[24] Youdas JW, Hollman JH, Krause DA. The effects of gender, age, and bodymass index on standing lumbar curvature in persons without current low back pain. Physiotherapy Theory and Practice. 2006; 22(5):229-37. [DOI:10.1080/09593980600927864] [PMID]

[25] Tsuji T, Matsuyama Y, Sato K. Epidemiology of low back pain in the elderly: Correlation with lumbar lordosis. Journal of Orthopaedic Science. 2001; 6(4):307-11. [DOI:10.1007/ s007760100023] [PMID]
[26] Marus SY, Gong WT, Rosha HL. The correlation between lumbar lordosis, L4-5-disc angle, L4-5 disc height, and the lumbosacral angle in L4-5 HNP patients. The Journal of Physical Therapy Science. 2010; 22(4):391-4. [DOI:10.1589/ jpts.22.391]

[27] Cho M, Lee Y, Kim CS. Correlations among sacral angle, lumbar lordosis, lumbar ROM, static and dynamic lumbar stability in college students. The Journal of Physical Therapy Science. 2011; 23(5):793-5. [DOI:10.1589/jpts.23.793]

[28] Razi N, Norasteh AA. [Compare thoracic kyphosis, lumbar lordosis, length of hamstring muscles and lumbar spine range of motion in high school students with and without non-specific low back pain (Persian)]. Journal of Zabol University of Medical Sciences and Health Services. 2015; 7(1):111

[29] Jang JS, Lee SH, Mintai JH, Maeng DH. Influence of lumbar lordosis restoration on thoracic curve and sagittal position in lumbar degenerative kyphosis patients. Spine. 2009; 34(32):280-4. [DOI:10.1097/BRS.0b013e318191e792] [PMID]

[30] Adams MA, Mannion AF, Dolan PP. Personal risk factors for first time low back pain. Spine. 1999; 24(23):2497-505. [DOI:10.1097/00007632-199912010-00012] [PMID]

[31] Been E, Kalichman L. Lumbar lordosis. The Spine Journal 2014; 14(1):87-97.

[32] Lin RM, Jou IM, Yu CY. Lumbar lordosis: Normal adults. Journal of the Formosan Medical Association. 1992, 91(3):329-33.

[33] Ball P, Cagle BE, Johnson CL, Lukert BP. Spinal extension exercises prevent natural progression of kyphosis. Osteoporosis International. 2009; 20(3):481-9. [DOI:10.1007/s00198008-0690-3] [PMID]

[34] Taweetanalarp S, Purepong N. Comparison of lumbar spinal angle between normal body mass index and overweight young adults. The Journal of Physical Therapy Science. 2015; 27(7):2343-6. [DOI:10.1589/jpts.27.2343] [PMID] [PMCID]

[35] Hegazy AA, Hegazy RA. Midsagittal anatomy of lumbar lordosis in adult Egyptians: MRI study. Anatomy Research International. 2014; 2014:370852. [DOI:10.1155/2014/370852] [PMID] [PMCID]

[36] Hay O, Dar G, Abbas J, Stein D, Masharawi Y. The lumbar lordosis in males and females, revisited. Plos ONE. 2015; 10(8):e0133685. [DOI:10.1371/journal.pone.0133685] [PMID] [PMCID]

[37] Giglio CA, Volpon JB. Development and evaluation of thoracic kyphosis and lumbar lordosis during growth. Journal of Children's Orthopaedics. 2007; 1(3):187-93. [DOI:10.1007/ s11832-007-0033-5] [PMID] [PMCID]

[38] Sidhu LS, Singal P. Age changes in kyphosis and lordosis of Jat-Sikh and Bania females of Punjab (India) from 20 to 80 years. Anthropologischer Anzeiger. 1983; 41(1):59-66. [PMID]

[39] Daneshmandi H, Kamali S, Aghayari A. [Development of Normal Back and Lumbar Spine Normals for High School Girls in Guilan Province (Persian)] [MSc. Thesis]. Tehran: Payam-e Noor University, Central Tehran Branch; 2009. 
[40] Rajabi R, Latifi S. [Normality of curvature of the back (kyphosis) and lumbar spine (Lordosis) of Iranian men and women (Persian)]. Research in Sport Sciences. 2010; 7:13-30.

[41] Sokhangouei Y, Asadi Saravi Kh, Asalemi M, Hemmatinezhad M. [The effect of hydrotherapy on some selected parameters related to kyphosis in kyphotic girls (Persian)]. Sport Sciences Quarterly. 2010; 2(3):77-93.

[42] Hart DL, Rose SJ. Reliability of a noninvasive method for measuring the lumbar curve. Journal of Orthopaedic \& Sports Physical Therapy. 1986; 8(4):180-4. [DOI:10.2519/ jospt.1986.8.4.180] [PMID]

[43] Hellsing E, Reigo T, McWilliam J, Spangfort E. Cervical and lumbar lordosis and thoracic kyphosis in 8, 11 and 15 year-old children. European Journal of Orthodontics. 1987; 9(2):129-38. [DOI:10.1093/ejo/9.2.129] [PMID]

[44] Torulf E. Spine: Posture, mobility and pain; A longitudinal study from childhood to adolescence. European Spine Journal. 2001; 10(2):118-23. [DOI:10.1007/s005860000230] [PMID] [PMCID]

[45] Milne JS, Williamson J. A longitudinal study of kyphosis in older people. Age and Ageing. 1983; 12(3):225-33. [DOI:10.1093/ageing/12.3.225] [PMID]

[46] Cherry DB. Review of physical therapy alternatives for reducing muscle contracture. Physical Therapy. 1980; 60(7):877-81. [DOI:10.1093/ptj/60.7.877] [PMID]

[47] During J, Goudfrooij H, Keessen W, Beeker TW, Crowe A Toward standards for posture: Postural characteristics of the lower back system in normal and pathologic conditions. Spine. 1985; 10(1):83-7. [DOI:10.1097/00007632-19850100000013] [PMID]

[48] Lindquist O, Bengtsson C, Hansson T, Jonsson R. Changes in bone mineral content of the axial skeleton in relation to aging and the menopause: Results from a longitudinal population study of women in Gothenburg, Sweden. Scandinavian Journal of Clinical and Laboratory Investigation. 1983; 43(4):333-8. [DOI:10.1080/00365518309168267] [PMID]

[49] Singer KP, Jones TJ, Breidahl PD. A comparison of radiographic and computer-assisted measurements of thoracic and thoracolumbar sagittal curvature. Skeletal Radiology. 1990; 19(1):21-6. [DOI:10.1007/BF00197923] [PMID]

[50] Goh S, Price RI, Leedman PJ, Singer KP. The relative influence of vertebral body and intervertebral disc shape on thoracic kyphosis. Clinical Biomechanics. 1999; 14(7):439-48. [DOI:10.1016/S0268-0033(98)00105-3]

[51] Mika A, Viswanath BU, Mika P. Differences in thoracic kyphosis and in back muscle strength in women with bone loss due to osteoporosis. Spine. 2005; 30(2):241-6. [DOI:10.1097/01.brs.0000150521.10071.df] [PMID]

[52] Sinaki M, Itoi E, Rogers JW. Correlation of back extensor strength with thoracic kyphosis and lumbar lordosis in estrogen-deficient women. American Journal of Physical Medicine \& Rehabilitation. 1996; 75(5):370-4. [DOI:10.1097/00002060-199609000-00013] [PMID] 
This Page Intentionally Left Blank 